\title{
Epistemologia das Ciências Humanas e Sociais
}

\author{
Katia Oliveira Lima ${ }^{1}$ \\ Gilson Vieira Monteiro²
}

Resumo: A transição da Idade Média para o Modernismo transformou de forma gradual a política, a sociedade e a economia, que passou do feudalismo para o capitalismo, logo em uma relação dialética influenciou no modo de perceber e investigar o mundo, inspirando a emergência de novas correntes filosóficas que subsidiaram o surgimento de novas ciências questionando as verdades até então inquestionáveis. Nas discussões sobre correntes filosóficas e científicas percebemos os conflitos e confluências entre diversas teorias. Iremos notar que algumas dessas correntes aceitam a influência externa para explicar os fenômenos, enquanto outras repudiam tal ideia buscando explicação em si mesma em uma perspectiva mais fechada. Essas aparentes dicotomias, por vezes dentro de uma análise mais profunda, se complementam a partir do olhar de alguns estudiosos ao perceberem os pontos de convergência entre elas. Nesse sentido propomos apontar as divergências e confluências entre as teorias que serão apresentadas bem como seus pressupostos e principais teóricos procurando refletir acerca das Ciências Humanas e Sociais a partir das teorias apresentadas, lembrando que as características de cada uma estão intrinsicamente ligadas ao contexto histórico.

Palavras-chave: Positivismo. Razão. Complexidade.

\footnotetext{
${ }^{1}$ Mestranda no Programa de Sociedade e Cultura na Amazônia pela Universidade Federal do AmazonasUFAM.

2 Doutor em Ciências da Comunicação pela Universidade de São Paulo. Professor associado II da Universidade Federal do Amazonas.
} 


\begin{abstract}
The transition from the Middle Ages to modernism turned gradually to politics, society and the economy went from feudalism to capitalism, then in a dialectical relationship influenced the way we perceive and investigate the world, inspiring the emergence of new philosophical currents, which supported the emergence of new sciences questioning the truths hitherto unquestioned. In discussions of philosophical and scientific currents, we see conflicts and confluences between different theories, we note that some of these chains accept outside influence to explain the phenomena, while others reject such an idea seeking explanation itself in a closer perspective, these apparent dichotomies sometimes within a deeper analysis complement each other, from the look of some scholars, to realize the points of convergence between them. In this sense we propose to point out the divergence and convergence between the theories to be presented as well as its assumptions and main theoretical, tries to understand the human and social sciences in from the theories presented, noting that the characteristics of each are intrinsically linked to the historical context.
\end{abstract}

Keywords: Positivism. Reason. Complexity. 


\section{Introdução}

No decurso da nossa vida acadêmica somos apresentados a inúmeras teorias científicas e filosóficas, mas por vezes de forma superficial. Logo, não conseguimos compreender as suas distinções tão pouco nos apropriar das suas características, o que dificulta nossa análise crítica na hora de escolher uma corrente filosófica ou método científico para nortear nossas investigações. Dada essa situação pretendemos abordar algumas teorias filosóficas e científicas, em especial as que estão correlacionadas às Ciências Humanas e Sociais, com o objetivo de contribuir para a compreensão destas diferentes correntes.

Para subsidiar nossa pesquisa recorreremos às bibliografias referentes à temática proposta, primeiro realizando um recorte histórico da filosofia e da ciência, trazendo para discussão teorias e métodos que as permearam, pontuando as divergências e convergências entre elas, ressaltando as contribuições desta relação ora dialética ora oposta para os avanços e desenvolvimento das sociedades. Buscaremos manter um diálogo entre filósofos e cientistas que influenciaram a Filosofia e a Ciência.

Para compreender as mudanças no modo a perceber o mundo e a as inter-relações e interinfluências entre essas transformações perceptivas e a Filosofia e a Ciência, é válido conhecer os períodos históricos e seus marcos, ou seja, quais as características que mais se evidenciam em cada um, assim como os estudiosos de cada época.

Por exemplo, a transição do período medieval para a era moderna trouxe grandes transformações para a sociedade, entre elas as formas de trabalho como reflexo da expansão comercial, logo, também para as relações sociais que foram modificadas nesse processo. Concernente à filosofia e à percepção de mundo, podemos dizer que a principal mudança foi a passagem do teocentrismo para o antropocentrismo, o que evidente no renascimento cultural e científico.

Nesse contexto o homem passa a ser o centro, as artes passam a figurar o homem e desta forma começa-se a questionar os dogmas religiosos, o que provocou alguns estudiosos a ir em busca de meios para chegar ao conhecimento verdadeiro.

Na busca por este método científico, o filosofo René Descartes adota a razão pura, que tem por princípio o pensar. A partir daí surgem estudiosos que irão admitir esse princípio e outros que o refutarão, assim apresentando outras teorias a fim de chegar ao conhecimento verdadeiro.

Nesse sentido versaremos sobre o método cartesiano a partir da razão fechada como oposto ao empirismo- experiência, apresentando as consequências dessa dualidade para 
as ciências, até chegar em teóricos que abordam e as percebem como complementares. Seguindo esta lógica chegaremos a ideia de complexidade e/ou de ecologia.

Nesse enredo pretendemos:

- Observar os pontos de vistas das diferentes correntes teóricas filosóficas e cientificas;

- Investigar as confluências e divergências existentes entre elas;

- Conhecer e reconhecer diferentes teorias epistemológicas.

\section{Transição da Idade Média para a Idade Moderna e as mudanças no pensamento científico}

Até a Idade Média ou período medieval que tem seu início com a queda do Império Romano Ocidental, mais especificamente no século V no ano de 476 d.C e seu declínio com a queda do Império Romano Oriental e de Constantinopla no século XV no ano de 1453, a economia girou em torno da agricultura. A sociedade manteve uma organização hierárquica tripartite: clero, nobres (aristocracia) e servos, na qual era muito difícil passar de uma classe a outra. A ideia de conhecimento que prevalecia era associado ao teocentrismo. Deus era o centro do universo e a fé e a autoridade da Igreja eram inquestionáveis.

Durante a Idade Média buscavam-se explicações e justificativas para os fenômenos naturais, culturais e econômicos nos dogmas religiosos da Igreja Católica. As literaturas eram basicamente teológicas. Nas artes, as pinturas e esculturas tinham como preocupação e objetivo retratar e corroborar com este pressuposto. Não considerava o belo, o estético da figura humana, retratava apenas as imagens divinas, a Santa Ceia, santos, as imagens da Sagrada Família.

Ainda no início do século XV, a Escolástica apesar de ser um modelo pedagógico nascido no século XI, mantinha-se forte. Este paradigma teve como precursor São Tomás de Aquino que "[...] soluciona as antinomias entre o aristotelismo e a filosofia cristã e elabora uma síntese entre o aristotelismo e a tradição herdeira do platonismo de Santo Agostinho" (CHIZZOTTI, 2014, p.10.) Conciliando fé e razão, cabe ressaltar que a razão da qual se fala aqui é a razão do inatismo, ideia de Platão que defende que temos ideias antes de nascer.

Nessa conciliação, Tomás de Aquino não sobrepôs razão sobre a fé afirmando que “- Fé e razão provêm ambas de Deus- logo, não se podem opor realmente. - No entanto, 
como a razão humana não pode ter a pretensão de ser a razão absoluta, deve aceitar o controle da fé". (Descartes, 2001, p. IX). Desta forma os dogmas da Igreja Católica ainda se mantinham relativamente fortes, pois o sistema de ensino basilar era centrado no método escolástico que tinha como pressuposto epistemológico refletir sobre fé e razão. Para tanto "propõe-se uma afirmação ou tese (pro) em que analisam as afirmações dos adversários e contestam a tese (sed contra), e finalmente, são apresentados os argumentos racionais para a solução[...]" (CHIZZOTTI, 2014, p. 09) e assim inúmeros pensadores foram formados.

Com o fim do período medieval, emerge a Idade Moderna na qual há a transição da economia feudal para a capitalista, que se fortalece por meio do comércio e das navegações e descobrimentos e colonização de novos territórios.

Nesse período a autoridade da Igreja passou a ser questionada. Houve um rompimento com os dogmas religiosos tidos como verdade absoluta, buscou-se colocar qualquer relação mística à margem enquanto ciência. Martinho Lutero liderou a Reforma Protestante, o teocentrismo deu lugar ao antropocentrismo, no qual o homem é o centro das reflexões, e passa a ser visto como ser dotado de razão e portanto pensante capaz de responder as questões que antes eram de domínio da Igreja. Sendo assim, ao invés de se buscar respostas para as questões dos fenômenos físicos e naturais, por exemplo, na religião e na fé, passou-se a usar a razão, polarizando em dois extremos de forma antagônica fé e razão, no sentido de que fé não se sobrepunha mais sobre a razão.

A partir da Idade Moderna, a ruptura entre Filosofia e Ciência se torna mais evidente pois a ciência moderna surge aceitando apenas os conhecimentos baseados apenas em evidências empíricas [...]. A filosofia busca construir conhecimento predominante a partir da razão" (VOLPATO, 2013, p. 04), nesse contexto surge o Renascimento.

\section{Renascimento}

No século XVI surge o Renascimento "provocado pelo desenvolvimento do comércio, da economia monetária, de novos conhecimentos e de invenções técnicas, que confluíram na renovação das artes, das ciências, do platonismo e da cultura europeia", (CHIZZOTTI, 2014, p. 11). A partir de então há a emergência de renovação cultural, artística, filosófica e científica. As artes nesse momento merecem um destaque especial, visto que passam de um extremo a outro, no instante em que as obras passam a retratar o homem em suas diferentes condições, apresentando nas pinturas e nas esculturas 
utilizando-se nessa da geometria para moldar a figura do homem naturalmente, mostrando a sensualidade, a beleza corporal, diferente das artes anteriores na qual o homem ficava em segundo plano, não podia retratar tais características humanas uma vez que as artes em geral até então eram basicamente religiosas e retratavam apenas as passagens bíblicas e imagens sagradas de Deus, anjos e santos. Dado esse novo modelo de desenvolvimento social, cultural e científico, os anseios da sociedade clamam um por um novo modo de investigação.

Uma das primeiras reivindicações e fortes aspirações da Renascença se cristalizava na exaltação e exigência da emancipação da razão. Que ela viesse reconquistar os espaços do saber e da normatividade da vida ocupados pela ortodoxia religiosa, imposta por pressão, se não por opressão autoritária. Em contraste com a Fé, entendida na estreiteza desse contexto inquisitorial, surgia a Razão também com maiúscula e designando o livre e autêntico pensar. (JOSAPHAT, 2003, p.2)

Como Josaphat aponta, a razão ressurge como meio de chegar ao conhecimento verdadeiro, e o método utilizado para alcançar a verdade é a verificação, sendo assim adotada em detrimento da fé para indicar os caminhos a serem seguidos.

Este foi um período de consideráveis avanços científicos. Tomamos como exemplo para ilustrar, o descobrimento do astrólogo Nicolau Copérnico, que mudou a concepção de universo ao afirmar que a Terra gira em torno do sol - heliocentrismo - colocando-o no centro do universo e refutando a teoria anterior de Ptolomeu que atestava que a Terra seria o centro do universo- geocentrismo - realizando assim uma descoberta extremamente importante para servir como base em diversas áreas do conhecimento. Outro fato que não podemos deixar de mencionar é a descoberta de Galileu Galilei, físico, matemático e astrônomo, nascido na Itália, que fez grandes descobertas astronômicas e construiu a primeira luneta -telescópio, o que lhe permitiu observar a lua e serviu de base, assim como a descoberta de Copérnico, para novas pesquisas. Podemos dizer que a partir de então as ciências começaram a evoluir.

[...] o Renascimento representa um período de magnificas conquistas. As grandes descobertas ampliaram a imagem do mundo. A astronomia modificou a concepção do universo. Os eruditos divulgaram as grandes obras do passado. Fizeram reviver doutrinas da Grécia e do Oriente: Platão, Plotino, O Estoicismo [...]. Enfim, o Renascimento deu aos homens, com vontade de ampliarem seus conhecimentos, o gosto pelo pensamento autônomo. (DESCARTES, 2001, p. $\mathrm{X})$. 
Mas cabe ressaltar que parte das descobertas realizadas no início do Renascimento, permaneceram por um longo tempo "engavetadas" visto que os cientistas tinham receio de publicá-las e serem julgados e condenados pelo Santo Ofício, por conta delas.

Em O mundo ou tratado da luz, Descartes desenvolvera, a propósito do problema particular da luz, as ideias diretrizes de sua física. A obra refutaria definitivamente a antiga cosmologia de inspiração aristotélica, ainda ensinada nas escolas, e fundaria, finalmente, o mecanicismo moderno dos modernos. Mas a doutrina era vinculada ás concepções heliocêntricas que, desde Copérnico, despertavam um interesse cada vez maior. Ora, o Santo oficio acabava de condenar Galileu, assustado, Descartes renunciou a publicação do livro. (DESCARTES, 2001, p. XVII).

Isso fez com que aumentasse a precaução por parte de outros cientistas e estudiosos em publicar seus escritos, com receio de não ter tanta sorte quanto Galileu, que apesar de ser condenado à masmorra e de ter seus livros proibidos de serem consultados e comercializados, teve sua pena amenizada, após renegar suas convicções. Essa liberdade do livre pensar e a ruptura emergente fortaleceu-se apenas no Iluminismo.

\section{Iluminismo}

Nesse momento iremos discutir a Teoria da Razão, que apesar de ser uma teoria nascida no século XV - Idade Moderna, que se consolidou no período conhecido como Iluminismo- ainda hoje é basilar para as diversas ciências. Discutiremos a cerca da teoria apresentando a resistência da Igreja Católica quanto a esse novo modo de ver as ciências e de investigá-las, buscando apresentar seus pontos positivos, negativos e contribuições para os avanços científicos e para o livre pensar.

Kant, em seu opúsculo Resposta à pergunta: O que é iluminismo de 1784, tece uma crítica ao teocentrismo, predominante na Idade Média, comentando que é mais confortável para o homem buscar explicações na fé e no modelo de razão por ela aceito, razão platônica ou escolástica, para os fenômenos em geral, do que pensar a respeito deles. $\mathrm{O}$ autor reflete também sobre como estes dogmas têm poder coesivo social imposto pela Igreja para manter a regulação e o conformismo. Mas com o advento do Renascimento há necessidade de uma ruptura dogmática.

Depois de terem emburrecido os seus animais domésticos e evitado cuidadosamente que estas criaturas pacificas ousassem dar um passo para fora de sua carroça que se encerram, mostravam-lhes o perigo que os ameaça se tentarem andar sozinhos. (KANT, 1784, p.02). 
Este trecho do folheto Resposta à pergunta: "O que é o Iluminismo? nos mostra a resistência da Igreja e o receio da grande massa em se aventurar por esta nova ótica, a do pensar de uma nova razão, nova porque até então segundo Cassirer, (1992, p.23 ) :

A razão é una e idêntica para todo o individuo pensante, para toda a nação, toda a época, toda a cultura. De todas as variações dos dogmas religiosos, das máximas e convicções morais, das ideias, e dos julgamentos teóricos, destacase um conteúdo firme e imutável, consistente, e sua unidade e consistência são justamente a expressão da essência da própria razão.

Mas com o desenvolvimento econômico e a necessidade do progresso de todos os demais setores da sociedade o homem sai da menoridade, por meio desse novo modelo de razão - ciência que não nos torna totalmente esclarecidos, pois a partir dela "temos apenas claros indícios de que se lhes abre agora o campo em que podem atuar livremente, e diminuem pouco a pouco os obstáculos à ilustração geral ou à saída dos homens da menoridade de que são culpados" (KANT, 1784, p.4), são responsáveis porque se permitiram dominar e condicionar.

Partindo dessa nova concepção de razão que se torna antagônica ao ponto de vista anterior, como explica Cassirer (1992, p.23), "a palavra razão deixou a muito tempo de ser uma palavra simples e unívoca". Durante essa transição entre Idade Média, Moderna e Iluminismo ela ganhou novo sentido, acepção esta que trouxe junto com ela a renovação do pensamento.

Dentre alguns cientistas e pesquisadores renascentistas e/ou iluministas, gostaríamos de destacar Descartes, nascido França no século XVI que apesar de não fazer parte, em vida, do movimento iluminista, defendia e ratificava os princípios do racionalismo e sua teoria cartesiana e foi basilar para progressos científicos alcançados a partir do Iluminismo ao se opor à educação escolástica que concilia fé e razão.

Descartes combate a instrução que recebeu do modelo escolástico propondo uma nova forma de conhecimento. Esse processo epistemológico instaurava a dúvida de todas as certezas antes postas, passando a questionar as verdades pré-estabelecidas. Sobre isso Descartes, em seu livro Meditações Metafisicas (1973, p.93) comenta que "há algum tempo eu me apercebi de que, desde meus primeiros anos, recebera muitas falsas opiniões como verdadeiras". Cabe ressaltar que Descartes não passou a desacreditar no divino Deus, apenas passou a ver de outro modo, se ele pensa em Deus, Deus existe, pois segundo Descartes a razão vem antes da experiência.

Com sua célebre frase "penso, logo existo", posta no seu livro "Discurso do Método" Descartes demonstra que percebe o indivíduo como ser pensante e conclui que 
até para duvidar das verdades postas é necessário pensar, mas para que este pensamento esteja ordenado e possa ser considerado válido é imprescindível que siga o método de verificação, que seja comprovado cientificamente. Desta forma aponta o conhecimento como fator inerente a consciência humana.

Com ânsia para acalmar a inquietação que o afligia, o pensador elaborou o método cartesiano, dedutivo, que consiste em duvidar, analisar, sintetizar e revisar o objeto de pesquisa fragmentado, que segundo Capra (1996, p.24) trata-se de um "método analítico, que consiste em quebrar os fenômenos complexos em pedaços a fim de compreender o comportamento do todo a partir das propriedades das suas partes". É um modelo no qual após o final desse processo de investigação não pode restar qualquer dúvida no resultado para que assim esse passe a ser considerado verdadeiro.

Nessa lógica os organismos vivos passam a ser vistos como máquinas altamente previsíveis.

Um físico importante que utilizou do cartesianismo, em especial a ideia do mecanicismo, foi Isaac Newton.

Apesar destas conquistas e avanços científicos, uma vez que contribuíram fortemente para a tecnologia, novas formas de trabalho, medicina, a emergência do livre pensar, o rompimento com os dogmas coesivos religiosos, as ânsias do novo modelo de sociedade que surgiu com o advento da navegações e novas demandas comerciais, este racionalismo fechado cartesiano ao qual o positivismo tem sua aproximação, que exclui tudo o que considera ruído, julgando como válido apenas as hipótese verificáveis de forma mensurável, sancionando como inverdade tudo que fuja a sua lógica, e que de acordo com MORIN (2010, p.159) "dispõe de uma visão do mundo comportando identidade do real, do racional, do calculável e de onde foram eliminadas toda desordem e subjetividade" excluindo a essência do ser, a mitologia, a ecologia, a complexidade, a condição humana, o cosmos, é danoso ao extremo no momento em que desconfigura os seres vivos e passa a tratá-los como máquinas, que teriam suas ações e reações previsíveis e provavelmente manipuláveis.

Partindo dessa ideia pretendemos realizar um diálogo entre a razão fechadapositivista que não erra é técnica, logo é pragmática e a razão aberta- ecológica que percebe não apenas o todo das estruturas, como também apresenta a ideia de interligação entre seres vivos, natureza e fenômenos, vendo-os como seres mutáveis e instáveis que estão em processo contínuo de formação, que são naturais, sociais, culturais cosmológicos, biológicos, físicos, portanto imprevisíveis. Buscaremos ponderar acerca 
das consequências metodológicas e epistemológicas que este pensamento racional, fechado e duro das Ciências Exatas que aceita apenas o que está dentro de uma lógica verificável, traz às Ciências Sociais, que tem explícita necessidade de ser compreendida em um contexto que tal teoria não abrange.

\section{Razão fechada e razão aberta}

Nosso objetivo é fazer aqui uma breve análise entre a razão mensurável fechada cartesiana postulada pelo filósofo, matemático e físico René Descartes, junto ao positivismo de Auguste Comte, considerado pai da sociologia e uma contraposição a esta ideia com a teoria mais atual como da complexidade defendida atualmente por diversos pensadores, entre eles Edgar Morin, sociólogo, nascido na França no século XIX, por uma razão aberta complexa, ecológica, que compreende o ser na sua totalidade, na qual a concebe a investigação cientifica, sabendo que as partes são mais do que o todo e o todo mais do que as partes.

Como já foi explicitado no capítulo anterior, o cartesianismo é mecanicista e exclui a ideia de mundo orgânico, assim o positivismo anos mais tarde serve-se deste método, que considera válido como ciência o que pode ser medido, comprovado, tornando-se indubitável. Cabe ressaltar que para Descartes o conhecimento parte do espírito humano e para Comte das observações externas, mas ambos buscam regras gerais.

De acordo com o positivismo, que tem o princípio do "ver para prever" (COMTE, 1978, p.20), por meio da ciência mensurável pode-se predeterminar as necessidades emergentes, assim como, permite manter a ordem na sociedade. Para Comte (1978, p.20) "a dinâmica social subordina-se à estática, pois o progresso provém da ordem e aperfeiçoa os elementos permanentes de qualquer sociedade: religião, família, propriedade, linguagem, acordo entre poder espiritual e temporal etc.". Isso quer dizer que a partir das observações, segundo a lógica positivista, se tornaria exequível lapidar as sociedades. Podemos perceber que o lema do positivismo era justamente a ordem e o progresso, não é por acaso que temos essas mesmas palavras na bandeira nacional brasileira.

A sociologia surge nesse contexto com o objetivo de investigar a sociedade como objeto, e o pesquisador deve manter a neutralidade durante a pesquisa, como se não fizesse parte desse objeto, "assim como quanto ao conteúdo social a apatia política se apresenta como politicum, também acontece quanto à enaltecida neutralidade científica" (ADORNO, 1996, p.141). É isso que nos faz refletir sobre esse modo positivista 
de pesquisar a sociedade, como algo separado, independente das ciências, na qual os pesquisadores devem manter-se distantes, como se não fizessem parte dela, pois para o positivismo " [...] em verdade, o conceito da sociedade seria, quanto ao conteúdo, o que os positivistas costumavam denominar de desprovido de sentido; nesta medida a sociologia, também como teoria crítica da sociedade, é "lógica"(ADORNO, 1996, p.140). Desconsiderando dentre outros, as subjetividades, o que não pode ser mensurado como por exemplo, os mitos.

Uma corrente filosófica que tem raízes no modelo positivista, mas que abriu o campo no momento em que aceita mitos, por exemplo, para fundamentar suas investigações no campo social é o Estruturalismo.

O percussor dessa corrente é Claude Levi Strauss, etnólogo francês, que estudou comunidades indígenas na Amazônia por um longo tempo. O pesquisador desenvolveu seu trabalho por meio da indução, buscando pontos de convergência sobre um mesmo tema em diferentes sociedades. O diferencial desta teoria é o fato deste etnólogo considerar os mitos, podemos citar para ilustrar melhor tal afirmação a observação que Levi Strauss faz ao comparar a validade ciência com a magia

Entre magia e ciência, a diferença primordial seria, pois deste ponto de vista, que uma postula um determinismo global e integral, enquanto que a outra opera distinguindo níveis, dos quais apenas alguns admitem formas de determinismo tidas como inaplicáveis a outros níveis. (p.32)

Desta forma buscando colocá-las não como duas polarizações antagônicas, e sim paralelas.

Não se pode negar que já foi um grande passo essa ruptura paradigmática, o fato de Levi Strauss ter confirmado para corroborar seus ensaios, no entanto, o fato de vivermos em um universo complexo, no qual tudo se encontra inter-relacionado, e que está em constante processo de transformação e pede de nós uma reforma de pensamento, que perceba o ser na sua complexidade.

Edgar Morin, em seu livro "Ciência com Consciência" expressa uma crítica à ideia da razão universal. Para ele o conceito de universalidade aparece como uma ideologia hegemônica e etnocêntrica, na qual algumas economias, sociedades sobrepujam-se sobre outras, moldando a sociedade conforme os mandos da hegemonia, o que já comentamos anteriormente quando falamos em positivismo, ordem e progresso.

Em congruência a esta percepção de mundo, Capra deixa claro em seus escritos que as problemáticas atuais se apresentam cada vez mais interligadas, sendo diferentes 
pontos de um mesmo holograma precisam, portanto, dialogar entre si, a fim de serem compreendidas.

Refletindo sobre as posturas de Morin e Capra, podemos dizer que não se deve romper com o contexto social, histórico e cultural, uma vez que estas características estão inter-relacionas. Tanto na teoria da complexidade de Morin quanto na ecológica de Capra, a razão é vista na sua dinamicidade e na sua interdependência com os saberes. Para Morin o que é tecido junto chama-se de complexo, e para Capra, Teia, muda a nomenclatura, mas a essência é basilar para ambos e é convergente, sendo assim, os dois concordam que a vida é eco-auto-reguladora.

Para que haja a eco-auto-organização Morin expõe o conceito de razão aberta que consiste em uma organização e reorganização entre campos que aparentemente são dicotômicos, mas na verdade são interdependentes. Para compreender esse processo não analisamos as partes separadamente, e sim, as contextualizamos no todo. A vida tem sua essência, mas necessita dialogar com o interno e externo para eco-auto-organização.

Há um todo complexo em uma célula, neste composto temos as informações necessária para identificar uma vida, mas essa célula não compõe o ser no seu todo, o todo é mais que isso dada as inter-relações, que depender dessa abertura dialética.

Uma observação importante que ilustra a razão aberta da fechada positivista é quem pela perspectiva sistêmica complexa fundamenta da relação de teia eco-auto-organizada é que não há hierarquia científica entre os campos. Afirmações ou fundamentações de artes têm o mesmo valor que a matemática, além disso dialogam entre si. Já no positivismo:

[...] matemáticas, astronomia, física, química, biologia e sociologia. As matemáticas possuem o maior grau de generalidade e estudam a realidade mais simples e indeterminada. A astronomia acrescenta a força ao puramente quantitativo, estudando as massas dotadas de forças de atração [...] (COMTE, $1978,22)$

Essa afirmação corrobora mais uma distinção entre complexidade e positivismo.

Cabe ressaltar que anteriormente e paralelamente a Morin e Capra, outros estudiosos já contribuíram para a percepção da vida na sua complexidade. Capra (1996) cita o filósofo Kant, o poeta Goethe, o pesquisador James Lovelock, o geólogo escocês James Hutton, o neurobiólogo Maturana. Sendo assim notamos, apesar de não se tratar de uma ideia recente, que essa mudança paradigmática torna-se cada vez mais emergente, em especial para as Ciências Sociais que, cada vez mais percebem o homem na plenitude. Partindo desse pressuposto iremos abordar, brevemente, as contribuições de Kant para a ciência e para o pensamento complexo. 
Immanuel Kant, filósofo do século XVII, já nos mostrava livro Crítica a Razão Pura, que empirismo e razão têm seus pontos positivos e negativos, além de não percebêlas como antagônicas. Nesta obra o autor tece uma crítica a razão pura, fechada, que encontra resposta em si mesma para tudo ao comentar que:

Não se pode duvidar de que todos os nossos conhecimentos começam com a experiência, porque, com efeito, como haveria de exercitar-se a faculdade de se conhecer, se não fosse pelos objetos que, excitando os nossos sentidos, de uma parte, produzem por si mesmos representações, e de outra parte, impulsionam a nossa inteligência a compará-los entre si, a reuni-los ou separá-los, e deste modo à elaboração da matéria informe das impressões sensíveis para esse conhecimento das coisas que se denomina experiência. (1781, p. 03)

Questionando o conhecimento a priori, como oposto a posteriori que precede a experiência à qual nos fornecer subsídios para compreender alguns fenômenos, acontecimentos e até prever de que forma se darão, em caso de reincidências ou similaridades, aqui percebemos uma crítica ao positivismo.

Immanuel Kant foi um dos grandes filósofos do Iluminismo e buscou meios de compreender o mundo pelo racionalismo e pelo empirismo, não como duas polaridades antagônicas, mas numa relação interdependente dialógica entre mundo interior e exterior. Para o filósofo uma parte do nosso conhecimento seria oriundo das experiências do contato com o mundo e outra parte teria origem a priori que ele chama de intuição. Segundo Buckingham, (2011, p. 171) "a teoria do idealismo transcendental de Kant afirma que tanto a razão quanto a experiência são necessárias para compreender o mundo" sendo, portanto, complementares e o empirismo passa a ser frutífero para as ciências.

Immanuel Kant foi um dos primeiros estudiosos pós-renascimento a perceber a natureza humana e a natureza ecológica na sua complexidade. Como nos diz Jordão (1992, p. 63):

Kant procurou que este reencontro se desse com a passagem dum pensamento fragmentário a um pensamento organizado pela ideia de um todo, que teria de assentar num princípio unitário, capaz de congregar todos os aspectos particulares num sistema em que estivesse implicada a influência recíproca das partes e fosse possível um juízo de valor sobre a existência humana.

Como já foi dito anteriormente, o positivismo percebia o homem e natureza como máquinas previsíveis, porém Kant foi de encontro a esta ideia defendendo que os organismos vivos são auto-organizados onde as partes são inseparáveis, logo é impossível compreender o todo sem compreender as partes, percebemos aqui que a ideia de complexidade não é tão recente quanto muitos podem imaginar. 


\section{Considerações Finais}

Esse trabalho propôs traçar uma sucinta retrospectiva de algumas correntes filosóficas e científicas preponderantes para o desenvolvimento e processo do conhecimento científico sabendo que muitas outras aqui não estão elencadas tiveram forte influência nesse percurso.

Ao refletirmos a cerca da mudança do pensamento aristotélico e teocêntrico para o racional e antropológico, acentuado no século XVI, percebemos os pontos positivos e negativos para as ciências, de um lado novas descobertas, de outro a fragmentação, a divisão do todo em partes que não se comunicam. Essa fragmentação exerceu forte influência no modo de fazer ciência.

Dentro deste discurso há um confronto ora explícito ora implícito entre racionalismo e empirismo. Nesse sentido procuramos encontrar pontos de convergência entre eles, e as inferências resultantes para o conhecimento científico.

Não podemos negar a importância de nenhuma destas correntes filosóficas e científicas, uma vez que todas dentro de um contexto histórico contribuíram de uma forma ou de outra para o progresso científico e para a ideia de homem, cultura, sociedade e cosmos, bem como para o surgimento de novas ciências.

Acreditamos que a percepção da complexidade sobre o sujeito e sua realidade, considerando-o nas suas multidimensionalidades, contribui de maneira mais eficaz para o resultado da pesquisa em detrimento do cartesiano. O modelo das ecologias não dispensa a rigorosidade cientifica, apenas recorrem a outros métodos.

Os pesquisadores sociais precisam escolher uma corrente para realizar suas investigações e nesse texto buscamos apresentar, as que isolam o homem como objeto e como pesquisador em polos distintos e as que os relacionam entre si e com o meio, mas para chegarmos a esta última foi necessário realizar uma retrospectiva histórica epistemológica.

Esperamos ter deixado claras as mudanças no modo de ver e fazer ciência, em especial após a ruptura com a filosofia da escolástica, assim como se deu o processo de mudança paradigmática epistemológica entre da sociedade medieval para a moderna, bem como suas influências para as ciências na atualidade. 


\section{Referências}

ADORNO, Theodor Wiesengrund. Textos Escolhidos. Coleção: Os pensadores. Traduções: Zeljko Loparic, et.al. — São Paulo: Nova Cultural, 1996.

BUCKINGHAM, Will. O livro da filosofia - Título original: The philsophy book. Tradução: Douglas Kim. São Paulo: Globo, 2011

CAPRA, Fritjof. A teia da Vida: Uma nova compreensão cientifica dos sistemas vivos. 11 ed. SP: Editora Cultrix, 1996.

CHIZZOTTI, Antônio. Apoio Didático das Aulas da disciplina Pesquisa em Educação. PUC-SP. São Paulo, 2014.

CASSIRER, Ernest. A Filosofia do Iluminismo. Tradução: Álvaro Cabral. Campinas: UNICAMP, 1992.

COMTE, Auguste. Seleção de textos de José Arthur Giannotti. Coleção: Os pensadores. Traduções de José Arthur Giannotti e Miguel Lemos. — São Paulo: Abril Cultural, 1978.

DESCARTES, René. Discurso Do Método. Tradução: Maria Ermantina Galvão. Revisão da tradução. MONICA STAHEL. Martins Fontes. São Paulo 2001.

, Meditações Metafísicas. In: Coleção Os Pensadores. Tradução, Bento

Prado Jr. São Paulo: Abril, 1973.

JORDÃO, Francisco V. NATUREZA, SENTIDO E LIBERDADE EM KANT. Revista Filosófica de Coimbra - 1 (1992), p 63-81. Disponível em: < http://www.uc.pt/fluc/dfci/ publicacoes/naturesa_sentido $>$ Acesso em: 10 de setembro de2016.

JOSAPHAT, Carlos. Fé e razão. Revista IDE. Janeiro /2013, p. 71-90. Disponível em: $<$ http://pepsic.bvsalud.org/pdf/ide/v36n56/v36n56a05.pdf > acesso em 10 de agosto de 2016 .

KANT, Immanuel. “Crítica da Razão Pura”. (1781). Tradução: J. Rodrigues de Merege. [s.d.] Créditos da digitalização: Membros do grupo de discussão Acrópolis. Disponível em < http://www.psb40.org.br/bib/b25.pdf> acesso em 08 de agosto de 2016.

. Resposta a pergunta: “O que é iluminismo?” (1784) Tradução

Arthur Mourão. [s.d.]. Disponível em < http://www.lusosofia.net/textos/kant_o_ iluminismo_1784.pdf $>$ acesso em : 11 de agosto de 2016.

LEVI-STRAUSS, Claude. O pensamento selvagem. São Paulo: nacional, p 19-55.

MORIN, Edgard. Ciência com consciência. Rio de Janeiro: Bertrand Brasil, 2016.

VOLPATO, Gilson. Ciência: da filosofia à publicação. 6 ed. São Paulo: Cultura acadêmica, 2013. 